\title{
REBELDIA DE UMA GERAÇÃO: O ZEN-BEAT ATRAVÉS DA LITERATURA DE JACK KEROUC.
}

\author{
Claudinei de Freitas Junior ${ }^{1}$ (História - UEL) \\ Crislayne Fátima dos Anjos ${ }^{2}$ (História - UEL)
}

\section{RESUMO}

Este artigo analisa a importância do movimento zen-budista nas teorias literárias de notório escritor do movimento Beat, Jack Kerouc. A geração Beat se desenvolveu na sociedade norte-americana entre as décadas de 1940 a 1960. Os beatniks, como eram denominados, eram indivíduos que adotaram um comportamento contrário aos padrões sociais e literários de sua época. O estilo de vida beat "se referia a um estilo de vida aventureiro adotado pelos que, sem eira nem beira, andavam a deriva pelas estradas da América em busca de aventura, aproveitando-se do American Way of Life" (BRANDÃO, 1990, p.26). Apesar de formarem um grupo, não adotaram um padrão literário, o que promoveu uma gama de estilos diversificados. Os escritores compartilhavam suas experiências literárias e questionavam a legitimidade de toda a autoridade instituída. Partindo dessa premissa, debruçar-nos-emos sobre a influência do pensamento zen-budista no estilo de vida beat de Kerouc, que através de seu estilo poético urbano, com uma linguagem de rua, transpareceu a suas experiências de maneira inovadora e pessoal.

Palavras-chave: Zen, movimento Beat, Jack Kerouc.

\section{JACK KEROUAC: O HACAÍSTA E CULTOR DO ZEN-BUSDISMO, A MENTE E O CORPO DA GERAÇÃO BEAT.}

Em meados de 1950 nos Estados Unidos iniciou-se um movimento sociocultural de grande repercussão que atingiram patamares de mudanças no campo artístico social, e uma diferente visão de mundo que perdurou em nossa atualidade. O movimento Beatnik, (uma fusão de Beat com Sputnik, a nave soviética lançada para o espaço na década de 1950), ou simplesmente a "Geração Beat", é considerada um dos primeiros movimentos de contracultura de nossa Era Moderna, uma avalanche em contrapartida do progressismo desenfreado norte-americano pós-segunda guerra mundial, e principal expoente influenciador de movimentos de grande barulho de décadas posteriores, como o movimento Hippie e Punk na década de 1970, e também o movimento feminista e homossexual que se fazem presente em nosso tempo. A Geração Beat foi um brado de revolta contra um sistema vigente, um grito de uma minoria que queria exprimir sua revolta perante um sistema caótico vigente.

O início e o marco da geração Beat deu-se através do poema "Uivo" de Allen Ginsberg, lido pela primeira vez em 1955, em um encontro de poetas e futuros nomes

\footnotetext{
1 Graduando em História pela Universidade Estadual de Londrina. E-mail: claudineijunior88@hotmail.com.

${ }^{2}$ Pós-graduanda de Especialização em Religiões e Religiosidades pela Universidade Estadual de Londrina. E-mail: cris laine1805@hotmail.com
} 


\section{SEMINÁRIO DE PESQUISA EM CIÊNCIAS HUMANAS - SEPECH \\ Humanidades, Estado e desafios didático-científicos \\ Londrina, 27 a 29 de julho de 2016}

do movimento, em um bar em São Francisco. Aliás, bares e tabernas tinham certos tabus perante a sociedade, pois eram lugares considerados sombrios, de difícil localidade e freqüentados por todos os tipos de pessoas. Ao embalo do Jazz, ritmo que era tocado em sua maioria por afro-americanos velhos distinguia uma melodia jovem em sua sonoridade, permitindo uma interação de indivíduos de diferentes idades, de diferentes etnias e que requeriam melhores condições de vida. Ginsberg é considerado o grande poeta de uma nova geração, tamanha influência que muitos jovens copiaram seus longos cabelos, sua barba e sua bata colorida durante a década de 1970 na geração Hippie.

No entanto o grande ícone da Geração Beat é Jack Kerouac, sua obra "On The Road" (1957) é considerada a bíblia do movimento Beat. Sua vida na estrada varreu a mentalidade de jovens descontentes, seu livro foi censurado e revisado diversas vezes antes de ser publicado, tamanho choque com a realidade era um tormento em uma sociedade totalmente conservadora. Kerouac juntou fragmentos de seu diário em que escrevia episódios de sua viagem e ordenou tudo em sua mística narrativa poética, a fusão de escritos de viagens, ânsia pela liberdade e uso abusivo de álcool e drogas, transformou Jack Kerouac em um célebre mártir da rebeldia jovem ocidental.

Os beatniks de Kerouac buscavam um estilo de vida que entrasse em conformidade com um sentido de vivência sem a correria cotidiana, em contraponto com a existência de milhares de pessoas frente ao caos urbano e o consumismo desenfreado. Jack Kerouc pretendia escrever de modo que a narrativa fluísse livremente. Para isso, entregava-se a descrição de cada detalhe da paisagem suburbana dos Estados Unidos e recorria à memória. Dessa forma, as frases não obedecem à uma ordem natural da sintaxe e formam longas digressões. Na realidade, Kerouc recusava-se a seguir um ideal de civilidade. Quando fazia suas viagens, na estrada da mente, buscava ser livre de uma sociedade que determinava o pensar e o agir.

E dentro das estruturas da geração Beat, nasce uma forma de influência mística oriental, o Zen-Budismo, outro universo cultural o qual propõe a prática para conseguir a possibilidade de alcançar a si próprio, o silêncio, a meditação e o desapego materialista. Segundo Bueno (1984), O Zen-Budismo foi fundamental no movimento de contracultura no ocidente:

O Zen entrou de qualquer forma em oposição a uma cultura verborrágica, palavrosa, cheia de retórica, mas mentirosa e injusta, extremamente materialista, que busca no conforto material todos os valores da vida, jogando para escanteio qualquer questão espiritual ou filosófica mais profunda. (BUENO, 1984, p. 23).

$\mathrm{O}$ zen tem sua origem ligada à história do Budismo, sua antiguidade remete a tempos tão longínquos que antecedem sua prática e disseminação no mundo Oriental e Ocidental. Seu início foi na Índia, onde Sidharta Gautama nasceu, entrou em uma busca profunda para atingir a iluminação e fundou a doutrina Budista. A palavra Buda significa "O desperto", "O iluminado". Em sua prática o Zen é transmitido de pessoa para pessoa, de um mestre na transmissão de ensinamentos práticos e teóricos à seus discípulos, e assim sucessivamente. É considerada a única doutrina que não utiliza manuscritos para disseminar a palavra. $\mathrm{O}$ zen é desenvolvido de maneira sentada 


\section{SEMINÁRIO DE PESQUISA EM CIÊNCIAS HUMANAS - SEPECH \\ Humanidades, Estado e desafios didático-científicos \\ Londrina, 27 a 29 de julho de 2016}

(Zazen), a base primordial, em verossimilhança com uma Flor de Lótus, no alcance de uma postura ereta e adequada para entrar em estado de meditação.

No Ocidente, mais especificamente na "Geração Beat", o Zen-Budismo foi difundido e incorporado através do contato de poetas e romancistas que iam ao Japão na busca por novas inspirações, nessas viagens eles depararam-se com os mosteiros onde a prática era ensinada. Durante o período de espera para a publicação de On the Road, Kerouac escreveu muitos outros. Escrevia em qualquer lugar, em qualquer momento, em qualquer condição. Era preciso realizar novas descobertas, encontrar novos caminhos. Nessa ocasião, o budismo apareceu como a descoberta de diferentes imagens para seus sentimentos religiosos.

Kerouac era filho de pais católicos, assim foi educado e permaneceu até seu falecimento. A crença no catolicismo não foi abandonada, ele, apenas estudou muito sobre o budismo em uma forma de encontrar consolação filosófica direta para os desapontamentos de sua vida. Como cita Chaters (1990, p.162): "Jack adotou a primeira norma do budismo acima de todas as outras, a afirmação de que "tudo na vida é sofrimento". Parecia mais pertinente, mais correspondente a seu estado de espírito do que a retórica bíblica do cristianismo. Seu budismo era uma questão emaranhada e pessoal, mas a atração mais imediata que exercia sobre ele que servia como defesa e como meio filosófico de justificar, perante si mesmo, seu sofrimento.

Kerouac começou seu livro desafiador de gêneros literários, Some Of the dharma, em 1953, como uma coletânea de notas de leitura de The Buddhist Bible; a iniciativa cresceu até tornar-se uma compilação maciça de material espiritual, meditações, orações e haicais, um estudo suas reflexões sobre os ensinamentos de Buda. Em 1955, enquanto morava com sua irmã na Carolina do Norte, trabalhou em outros dois textos relacionados com budismo: Despertar e Buddha Tells Us, traduções de "obras do grande rimbaudiano francês nas abadias do Tibete", às quais se refere em suas cartas como "um amplo manual budista. (WEINREICH, 2013, p.12).

O zen para Kerouac foi algo que sobrou do Budismo original, quando passou para a China, e de lá para o Japão. A parte Zen que influenciou sua obra foi o Zen presente nos Haicais, poemas de três versos e dezessete sílabas escritas há séculos. $\mathrm{O}$ Haicai chegou a Jack Kerouac através de Gary Snyder, poeta que passou o começo da década de 1950 viajando pelo Japão, estudando e praticando o Zen-budismo. Kerouac e Snyder passaram um tempo juntos em Berkeley, em 1955, bebendo, conversando e trocando suas próprias traduções e versões de haicais de Reginald H. Blyth (o maior estudioso da cultura japonesa de seu tempo) sobre as obras japonesas. Nesse estudo e grande influência oriental, Kerouac encontrou novas afinidades emotivas e estéticas, e abriu uma nova etapa pioneira, intitulando-se Haicai Pop, uma adaptação do estilo japonês, uma nova forma poética e inovadora em solo americano."Peeking at the moon/ in January Bodhisattva/ Takes a secret piss" (KEROUAC, 1959)

Nesse Haicai, Kerouac demonstra seu lado excêntrico de escrita, ao mesmo tempo em que Bodhisattva, aquele que corajosamente aspira pela iluminação e contempla a bela forma da simplicidade de um luar de Janeiro, Kerouac algazarra à

\footnotetext{
${ }^{3}$ Espreitando a Lua/De janeiro, Bodisattva/Dá uma discreta mijada.
} 


\section{SEMINÁRIO DE PESQUISA EM CIÊNCIAS HUMANAS - SEPECH \\ Humanidades, Estado e desafios didático-científicos \\ Londrina, 27 a 29 de julho de 2016}

contemplação espiritual budista na figura do iluminado à sua necessidade fisiológica. $\mathrm{O}$ poeta em suas linhas demonstra a busca pela pureza e usa a extravagância típica beat em pequenas linhas "Haiku, Shmaiku, I can't/ understand the intention/ Of reality" (KEROUAC, (1953-1956).

Kerouac, neste outro haicai demonstra o drama que esteve presente em toda sua vida, a busca por algo que pudesse contemplar em sua essência. Desde viagens pela costa dos EUA, montanhas isoladas, pequenas cidades, Jazz, Drogas, festas abusivas, diários, livros, Budismo. Kerouac foi uma metamorfose vivente, vivia entre a linha tênue da calmaria e o caos, em busca da compreensão da realidade.

É verdade que o haicai, como o zen, valoriza a beleza do que é modesto e simples (e não do que é sofisticado e cheio de ornamentos inúteis). Mas o haicai não é, no fundo, o que se vê; é o que se diz sobre o que se vê. Por isso não é zen, porque o zen não admite nenhum tipo de símbolo ou representação da realidade (e a linguagem é um sistema de símbolos). Poder-se-ia afirmar com razoável segurança que a "Primeira Nobre Verdade" do budismo é a única verdade que interessa ao haicai. O que há em comum entre haicai e zen-budismo é apenas a premissa de que todas as coisas são impermanentes, todas as coisas são imperfeitas e todas as coisas são incompletas. Assim, no haicai, aprecia-se o amor à natureza e a todos os seres, o despojamento e a simplicidade, mas não (salvo exceções) a irreverência e o paradoxo. O fato é que não é preciso ser beat nem hippie nem zen nem filósofo - nem muito menos poeta - para fazer haicai. Basta ser haicaísta.

O haicai é hoje em dia o tipo de poema mais produzido e divulgado em todo o mundo, tanto individualmente quanto em congregações ou grêmios que reúnem os adeptos e promovem concursos e oficinas o ano inteiro. Cada país tem a sua própria "escola haicaística", sucessora da herança literária dos grandes clássicos japoneses, dentre os quais Matsuo Bashō (1644-1694), considerado o fundador do gênero. Foi Bashō quem descobriu as potencialidades de expressão dessa forma poética, então chamada de hokku, que ele destacou de um gênero mais amplo denominado haikai no renga. Na poética japonesa, a beleza é impregnada pelas noções de uma nostálgica solidão existencial ( $s a b i$ ) e uma austera humildade (wabi), ambas centradas no "aqui e agora" que é a marca da evanescência zen-budista com que os seres e as coisas são vistos num haicai. Escolhi três textos representativos da temática haicaística de Bashō com o intuito de demonstrar que Kerouac, à parte os exageros de seu envolvimento com a filosofia zen, soube traduzir essa temática em seus haicais. Os poemas originais estão em romaji, que é a transliteração da escrita japonesa para o alfabeto latino.

Nestes Haicais de Kerouac extraídos do livro de Weinreich (2003) nos traz suas percepções pioneiras desse gênero literário. "All day long wearing/ a hat that wasn't/ On my head" $\mathrm{e}^{5}$ "In my medicine cabinet/the winter fly/Has died of old age $\mathrm{e}^{6 "}$.

Estes dois poemas, são bem característicos das suas duas abordagens haicaísticas mais constantes (e conflitantes). $\mathrm{O}$ primeiro reflete a forte influência que uma visão simplista do zenbudismo de que já se falou aqui, repleta de absurdos e contradições, teve sobre o autor, e o outro é mais voltado para a linha tradicional. Pode-se ver que nesse último poema o termo de estação está explícito e a abordagem do transitório é

\footnotetext{
${ }^{4}$ Haicai Shmaicai, não consigo/ entender a intenção/ da realidade.

${ }^{5}$ Uso o dia inteiro/Um chapéu que não estava/Na minha cabeça.

${ }^{6} \mathrm{Na}$ mosca do inverno/No armário dos remédios/Morreu a velhice.
} 


\title{
XI SEMINÁRIO DE PESQUISA EM CIÊNCIAS HUMANAS - SEPECH \\ Humanidades, Estado e desafios didático-científicos \\ Londrina, 27 a 29 de julho de 2016
}

bem marcada pela mosca que, por ironia, cercada de drogas que lhe eram inúteis, não escapou da morte.

Esses modos de percepção do real típicos do haiku japonês foram captados por Kerouac, que lia os poemas de Bashō. O Zen Beat de Jack Kerouac é uma rede de várias vias, usa o Zen para justificação e o capricho de sua arte, uma forma subjetiva de manifestar sua rebeldia entrelaçado com a suavidade do Zen. O Budismo permaneceu para ele como um interesse literário, não como uma prática espiritual e de meditação. De acordo com Allan W. Watts:

\begin{abstract}
A mentalidade beat, tal como eu a vejo, é alguma coisa ao mesmo tempo mais extensa e mais vaga do que o tipo de vida "de vanguarda" que se vive em Nova York e São Francisco. Trata-se de uma geração de jovens que se recusa a participar do "estilo norte-americano de viver", uma revolta que não quer mudar a ordem existente, mas simplesmente dá-lhe as costas e procura o significado da vida na experiência subjetiva, em vez da realização objetiva. Contrasta com a mentalidade square e com outras formas em que se é iludido pelas convenções sociais, sem tornar conhecimento da correlatividade do certo e do errado, da necessidade recíproca de capitalismo e comunismo coexistirem, da identidade íntima entre o puritanismo e a lascívia, ou, digamos, da aliança dos grupos de pressão da Igreja e do crime organizado para que sejam mantidas as leis contra o jogo. (WATTES, 1988, p. 86).
\end{abstract}

A conjunção multicultural literária na carreira de Jack Kerouac é a obra os Vagabundos do Dharma de 1958. Nela é exposto claramente à influência e a adaptação do Zen-Budismo, dando luz a uma narrativa romancista diferenciada em solo norteamericano na busca pela iluminação de Buda, o Zen-Beat dos Vagabundos, como diz o próprio título do livro. Os Vagabundos do Dharma segue a mesma linha de narrativa do clássico On The Road, com a referência à herança oriental. O livro narra o reencontro e despedida de dois amigos, Ray Smith, um escritor em busca de si próprio, um pseudônimo representando a figura de Jack Kerouac. O Outro personagem é Japhy Rider, um poeta, haicaísta, zen-budista que estava de partida para o Japão, para estudar filosofias orientais, que representa o grande influenciador oriental de Kerouac, Gary Snyder.

Japhy Rider tem um caráter místico e contemplativo e, sempre invocando a sabedoria do zen-budismo, que prega de um modo e vivencia de outro, "curte a vida adoidado", em busca da realização espiritual que só através do darma, a doutrina do Buda, pode ser alcançada. Há muita contradição e pouca realização ou iluminação nesse modo hedonista, irresponsável e boêmio de budismo, e Kerouac foi contestado em seu tempo pela estreiteza de visão em relação aos valores da religiosidade japonesa. Mas o fato é que, bem ou mal, é nessas conversas informais, entre uma ou outra excursão e uma e outra garrafa, que Japhy Rider (Gary Snyder) ensina a arte do haicai a Jay Smith (Jack Kerouac), como a expressão literária típica, em sua (equivocada) opinião, da filosofia zen-budista e, por extensão, da cultura oriental. $\mathrm{O}$ curto romance assemelha a geração beat com os monges andarilhos Japoneses que buscavam sua iluminação, saindo dos mosteiros, percorrendo grandes distâncias, escalando montanhas e apreciando as paisagens. Os vagabundos de Kerouac faziam quase a mesma trajetória 


\section{SEMINÁRIO DE PESQUISA EM CIÊNCIAS HUMANAS - SEPECH \\ Humanidades, Estado e desafios didático-científicos \\ Londrina, 27 a 29 de julho de 2016}

espiritual, a diferença é que o cenário da História é complementado com orgias regadas a vinho, cantos e poemas zen, e algumas aventuras sexuais bem intensas.

O Zen-Beat de Kerouac é a libertação de padrões pré-estabelecidos da sociedade em que viviam, a busca pelo seu interior, a tentativa de alcance da iluminação de Buda em linhas distorcidas. Ao mesmo tempo, a liberdade debruça aos prazeres mundanos, fazendo aquilo que quiser na conformidade da pura vontade dos desejos. O Vagabundos do Dharma é uma faca de dois gumes, onde a harmonia e o caos se complementam. Allan W. Watts enfatiza o pensamento dizendo: “[...] para o Zen Beat, não há necessidade de nenhum esforço, de nenhuma disciplina, de nenhum empenho especial para se chegar ao satori, ou para se chegar a ser o que já se é.” (WATTS, 1988, p.101).

As críticas à Kerouac, principalmente de Watts vêm justamente ao modo errôneo da busca espiritual, muitas vezes seu Zen-Beat é tratado com algo sem importância alguma, pois o mesmo não segue a doutrina Original. Sua experiência de despertar é associado a um estilo de vida de extrema loucura, nunca foi a intenção de Kerouac seguir a prática (Zazen), o total desapego e a quietude espiritual. $\mathrm{O}$ beatnik infiltrou-se totalmente na estética zen-budista, o modo de vida oriental foi um meio de metamorfosear sua literatura e dar um novo sentido de interpretação do mundo, como também a criação de uma nova forma poética que se estendeu por mais variados lugares e influenciou milhares de pessoas e gerações posteriores.

\section{BIBLIOGRAFIA}

BUENO, A; GOÉS, F. O que é Geração Beat. São Paulo: Brasiliense, 1984.

CHARTERS, Ann. Kerouac: uma biografia. Rio de Janeiro: Campus, 1990.

KEROUAC, JACK.. Livro de Haicais. Tradução de Claudio Willer. Porto Alegre: L\&PM, 2013.

KEROUAC, JACK. Os Vagabundos do Dharma. Tradução e prefácio, Margarida Vale de Gato. Lisboa: Relógio D’água Editores. Lisboa, 2000.

WATTS, Alan W. O Zen e a Experiência Mística. São Paulo, Cultrix, 1988.

WEINREICH, REGINA. Introdução ao Livro de Haicais. Tradução de Claudio Willer. Porto Alegre: L\&PM, 2013. 